\title{
Optimal Strategy for selling on Group-buying Website
}

\author{
Xuan Jiang, Shiming Deng \\ School of Management, Huazhong University of Science and Technology \\ judjx.jiang@gmail.com,.smdeng@bust.edu.cn
}

Received: April 2014

Accepted: June 2014

\section{Abstract:}

Purpose: The purpose of this paper is to help business marketers with offline channels to make decisions on whether to sell through Group-buying (GB) websites and how to set online price with the coordination of maximum deal size on GB websites.

Design/methodology/approach: Considering the deal structure of GB websites especially for the service fee and minimum deal size limit required by GB websites, advertising effect of selling on GB websites, and interaction between online and offline markets, an analytical model is built to derive optimal online price and maximum deal size for sellers selling through GB website.

This paper aims to answer four research questions: (1) How to make a decision on maximum deal size with coordination of the deal price? (2) Will selling on GB websites always be better than staying with offline channel only? (3) What kind of products is more appropriate to sell on GB website? (4) How could GB website operator induce sellers to offer deep discount in GB deals?

Findings: This paper obtains optimal strategies for sellers selling on GB website and finds that: Even if a seller has sufficient capacity, he/she may still set a maximum deal size on the GB deal to take advantage of Advertisement with Limited Availability (ALA) effect; Selling through GB website may not bring a higher profit than selling only through offline channel when a GB site only has a small consumer base and/or if there is a big overlap between the online and offline 
markets; Low margin products are more suitable for being sold online with ALA strategies (LPALA or HP-ALA) than high margin ones; A GB site operator could set a small minimum deal size to induce deep discounts from the sellers selling through GB deals.

Research limitations/implications: The present study assumed that the demand function is determinate and linear. It will be interesting to study how stochastic demand and a more general demand function affect the optimal strategies.

Practical implications: This paper provides a very useful model framework and optimal strategies for sellers' selling on GB website. It takes advantage of the analytical model to explain much typical practical phenomenon for E-commerce like free sale with limited availability and so forth. It also helps GB website operator to induce deep discount from sellers.

Originality/value: This paper is a first attempt to examine the seller's GB sale decision problem regarding to price and bounds on deal sizes. It analyses how the minimum deal size set by the GB website affect the optimal decision of sellers'. Moreover, it also discusses the impact of the interactions between online and offline markets on sellers' decision.

Keywords: group-buying, pricing, deal size, advertisement, dual channel

\section{Introduction}

Groupon is a first famous group-buying website born in USA in 2008, after which Group-buying (short for GB hereafter) websites spring up all over the world quickly. It is reported that the volume of transaction on GB websites in China is about 59.8 billion USD in 2013, which increases by $67.7 \%$ compared with that in 2012 . However, not all the deals on GB websites could benefit sellers. Dolakia (2011) surveyed 324 sellers who ever sold products/offered service through GB websites such as Groupon, LivingSocial, Open Table, Travelzoo and BuyWithMe. The result shows that $55.5 \%$ of the deals on GB websites made money, $26.6 \%$ lost money and $17.9 \%$ broke even.

Deals on GB website are distinguished from the other traditional promotions by the most typical character that GB website operator sets the minimum deal size for each deal on the GB website. Only when the number of consumers buying the product exceeds the minimum deal size can the GB deal be valid. This also means sellers should sell the least quantity of the valid deal which is equal to the minimum deal size set by the GB website. This can help GB website operator guarantee the least revenue from each valid deal in case that sellers use the platform as an advertising tool by a free ride. Besides, a GB website operator also charge GB sale fees from sellers. A seller selling on the GB website can decide the price and weather to set a 
maximum deal size on the deal. If a maximum deal size is made, consumers beyond this size would miss the deal.

Selling on GB websites is analogous to making an advertisement for the products because sellers could reach a mass of new consumers affiliated to GB websites (Dholakia \& Tsabar, 2011; Edelman, Jaffe \& Kminers, 2011; Zhang 2009; Tuten \& Ashiley, 2011). A number of sellers take advantage of setting a low price as well as maximum size on deals to attract many new consumers and limit them to buy the products, hence, they can transfer lots of consumers who miss the GB deals to buy offline where the cost for sellers is much lower and the price may be higher (Luo, Andrews, Song \& Aspara, 2013). In this paper, we call this phenomenon as Advertisement with Limited Availability (short for ALA hereafter). However, a maximum size on GB deal may also lead to consumers hold-back behavior-consumers who miss the GB deal due to the upper size limit may turn to other substitute product, or defer to purchase in the expectation of future promotion. Based on consumers' behavior, we study on whether consumers should set maximum deal size and how to set the maximum deal size with coordination of the deal price?

Selling on GB websites also introduces a market spill-over effect. Existing offline customers may take advantage of the discounts. On the other hand, new online consumers are generally more price sensitive and less valuable than loyal consumers ( $\mathrm{Li}$, Sycara \& Scheller-Wolf, 2010; Hoch, Kim, Montgomery \& Rossi, 1995; Anily \& Hassin, 2013; Chen, Kauffman, Liu \& Song, 2010). An article in Wall Street Journal (January 7, 2011) reports U.S. Toy Co., a family-owned toy retailer with eight stores across the country, drew nearly 2800 consumers by the daily deal on Groupon, but new consumers are very limited and they spent less than the average amount. So a question arises naturally: Will selling on GB sites always be better than staying with offline channel only?

Some extant empirical literatures (Qian, 2013; Zhang 2013) and business analysis report (CECRC, 2012) show that the most popular items sold on GB websites include restaurants, spas, sporting events and cinemas. Zhang (2013) observe that Groupon always like to choose high margin items to be daily deals in order to obtain a gross profit rate over $10 \%$. In this research we use an analytical model to analyze what kind of products is more appropriate to sell on GB website in virtue of the advertising effect.

Consumer coupons are widely used as promotion tools, some scholars have already studied the joint decision on the consumer coupons between department and retailers or between manufacturers and retailers (Geng \& Mallik, 2011; Demirag, Keskinocak \& Swann, 2011; Aydin \& Porteus, 2009). To our best knowledge, there is no literature about the relationship between GB website operator and sellers on the consumer coupons. Actually, the website operator would like to make sellers offer deep discount in a daily deal so as to keep competitive to other 
similar GB websites. In this research we show how GB website operator could induce sellers to offer deep discount in GB deals.

The extant literatures always focus on comparison of the mechanisms between sales on GB website and traditional promotions, and the mechanism design for GB website (Anand \& Aron, 2003; Jing \& Xie, 2011; Hu, Shi \& Wu, 2013). Differentiated from these researches, we take into account the format of prevailing GB website especially the minimum deal size and commission fee set by the GB website operator, the interactions between online market and offline market and consumers' behavior, then we analyze sellers' optimal strategies including pricing and setting maximum deal size on the GB deal and discuss how the strategies vary with the factors considered in the model.

\section{Model Set-up}

This paper researches on a decision problem on the cooperation with GB website for sellers who initially sell products/offer service through offline channel. Considering interactions between GB website and offline channel, the model structure is as following:

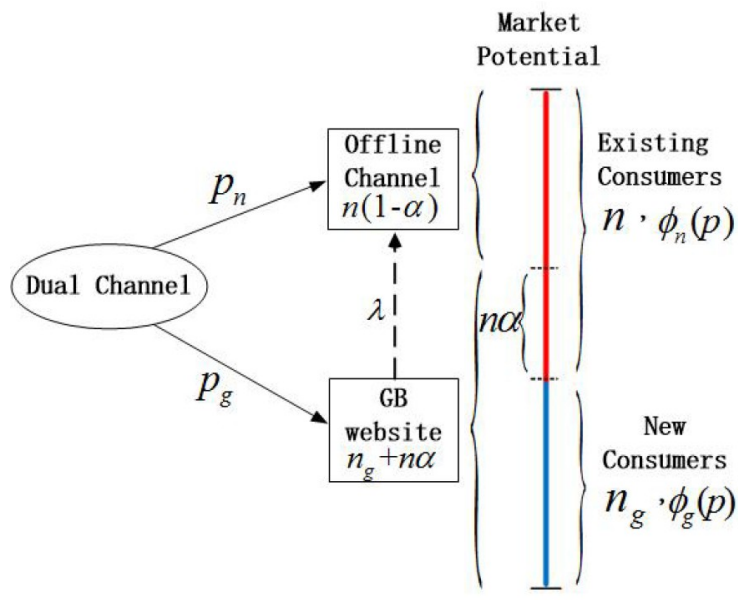

Figure 1. Interactions between Group-buying website and offline channel

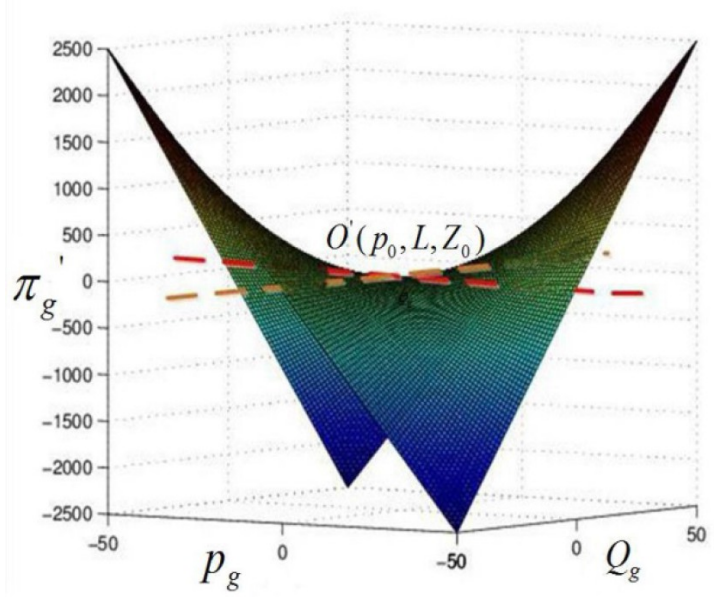

Figure 2. Seller's profit function in three-dimension 
The notations of the parameters are as following:

$n=$ Market size for existing consumers

$n_{g}=$ New consumers brought to sellers by the GB website

$\alpha=$ Proportion of the existing consumers using the GB site, which is the overlap between online and offline market

$p_{n}=$ Price for sellers selling through offline

$c_{n}=$ Cost per product for sellers selling through offline

$c_{g}=$ Cost per product for sellers selling through GB website, $c_{g} \geq c_{n}$

$I_{g}=$ Minimum deal size for a deal on a GB website to be valid

$\varphi_{n}(p)=$ Demand rate of existing consumers who buy the product at price $p$

$\varphi_{g}(p)=$ Demand rate of new online consumers who buy the product at price $p$

$D_{g}(p)=$ Online demand for the product when price is at $p$

$\lambda=$ Retention rate of consumers who miss the deal on GB website due to the maximum deal size but also would like to transfer to search the product offline, $0 \leq \lambda \leq 1$

$Q_{g}=$ Actual number of products sold through GB website for the deal

$Q_{n}=$ Purchasing quantity from existing consumers who do not see the information on the GB website

Sellers decision variables:

$p_{g}=$ Price for sellers selling through GB website

$U_{g}=$ Maximum size limit set by the sellers for the GB deal

Existing consumers and new consumers from GB website are heterogeneous. We assume that demands are linear in price $p$ but have different price sensitivity (Anand \& Aron, 2003). The demand rate of existing consumers who would buy the product at $p$ is $\varphi_{n}(p)=1-m p, \varphi_{n}$ $(p) \in[0,1]$. The demand rate of new consumers from GB sites who would buy the product is $\varphi_{g}(p)=1-r p, \varphi_{g}(p) \in[0,1]$. We assume $m \leq r$ because new online consumers are generally more price sensitive and less valuable than existing consumers (Li, Sycara \& Scheller-Wolf, 2010; Anily \& Hassin, 2013). 
GB websites always require sellers to set a price in the deal at least not higher than that in offline channel so that to maintain the competitive advantage and their credit as daily deal sites that guarantee consumers lower prices, so we assume $p_{g} \leq p_{n}$ in this paper. We also assume that offline prices keep unchanged even if sellers also sell products on GB website. This assumption is in line with the reality that there is no restaurant or cinema changes the offline price after the cooperation with GB website.

When coupons are offered on GB websites, spill-overs may happen. That is, a portion of existing offline consumers, $\alpha \in[0,1]$, may also visitors of the GB websites and choose to buy online because of the discount as well as the convenience. Therefore, the demand from the existing consumers buying from offline will reduce to $Q_{n}=(1-\alpha) n \varphi_{n}\left(p_{n}\right)$.

Consumers purchasing GB coupon consists of two groups - new consumers from GB sites and existing consumers exposed to GB coupons. If the seller sets the GB price at $p_{g}$, the mixed online demand is as follows.

$$
\begin{aligned}
D_{g}\left(p_{g}\right) & =n_{g} \varphi_{g}\left(p_{g}\right)+n \alpha \varphi_{n}\left(p_{g}\right) \\
& =n_{g}+n \alpha-s p_{g}
\end{aligned}
$$

Where $s=r n_{g}+\alpha m n$, which is the aggregate consumers' price sensitivity of the mixed demand.

The main difference between sales on GB website and traditional promotions is that GB website operator set a minimum deal size $I_{g}$. The number of consumers buying the products should be at least equal to the minimum deal size, otherwise, the deal will not be valid and the GB website will refund the consumers who have already paid on the GB website.

As stated in Introduction, some extant literatures have already shown that selling online can be a tool to attract new consumers and transfer them to offline channel. In the real world, many sellers sell products at an extremely low price or sell for free through GB website, for example, limited sales for the opening ceremony of new estate and limited sales for luxury products on GB website, so that they can attract a mass of consumers and transfer part of them to offline. If sellers set maximum deal sizes $U_{g}$ on the deal of GB website, the actual quantity of products sold through GB website is $Q_{g}=\min \left\{D_{g}\left(p_{g}\right), U_{g}\right\}$. If $U_{g} \leq D_{g}\left(p_{g}\right)$, we have $U_{g}=Q_{g}$. The number of consumers who miss the deal due to the upper size limit is $D_{g}\left(p_{g}\right)-Q_{g}$.

Among the consumers missing the deal, $D_{g}\left(p_{g}\right)-Q_{g}$, a portion of them are new consumers and the rest are existing ones. Because every consumer is equally likely to visit the GB site and shift to offline, the portions of new consumers and existing ones are proportional to their corresponding percentage population in all online consumers, that are, $\frac{n_{g}}{n_{g}+n \alpha}$ and $\frac{n \alpha}{n_{g}+n \alpha^{\prime}}$ 
respectively. The shifting consumers make purchase decision based on the offline price, $p_{n}$. Therefore, the total offline demand from these consumers is:

$$
\lambda\left(D_{g}\left(p_{g}\right)-Q_{g}\right)\left[\varphi_{n}\left(p_{n}\right) \frac{n \alpha}{n_{g}+n \alpha}+\varphi_{g}\left(p_{n}\right) \frac{n_{g}}{n_{g}+n \alpha}\right]
$$

We define, $B=\lambda\left[\varphi_{n}\left(p_{n}\right) \frac{n \alpha}{n_{g}+n \alpha}+\varphi_{g}\left(p_{n}\right) \frac{n_{g}}{n_{g}+n \alpha}\right], B \in\left(\lambda \phi_{g}\left(p_{g}\right), \lambda \varphi_{n}\left(p_{n}\right)\right)$. It means the percentage of consumers who shift from online to offline AND buy the product at the offline price $p_{n}$. Hereafter we call $B$ is the transfer- and- buy rate.

This paper makes the sellers' profit of selling through GB website as the objective function and the optimization problem is as following

$$
\begin{gathered}
\text { (P1) } \max _{p_{g, U_{g}}} \pi_{g}=Q_{g}\left(p_{g}-c_{g}\right)+B\left(D_{g}\left(p_{g}\right)-Q_{g}\right)\left(p_{n}-c_{n}\right)+\pi_{g 1} \\
\text { s.t. } Q_{g}=\min \left\{U_{g}, D_{g}\left(p_{g}\right)\right\} \\
Q_{g} \geq I_{g} \\
0 \leq p_{g} \leq p_{n}
\end{gathered}
$$

The objective function includes three parts. First term, $Q_{g}\left(p_{g}-c_{g}\right)$, represents seller's profit directly from GB website; Second term, $B\left(D_{g}\left(p_{g}\right)-Q_{g}\right)\left(p_{n}-c_{n}\right)$, means seller's profit from the transfer consumers who miss the deal on GB website due to the maximum deal size and buy products offline; Third term, $\pi_{g 1}$, is the profit from offline existing consumers who do not know the deal on the GB site. Because $p_{n}$ is fixed, thus $\pi_{g 1}=Q_{n}\left(p_{n}-c_{n}\right)=(1-\alpha) n \phi_{n}\left(p_{n}\right)\left(p_{n}-c_{n}\right)$ is constant. We can omit it in later discussion.

From ( $p 1$ ) we can see that $Q_{g}$ and $U_{g}$ are not independent. When $Q_{g}<D_{g}\left(p_{g}\right)$, the maximum deal size takes effect and we can infer $U_{g}$ form the value of $Q_{g}: Q_{g}=U_{g}$. When $Q_{g}=D_{g}\left(p_{g}\right)$, it means sellers have not set effective maximum deal size and we can infer $U_{g}$ can be any value that belongs to $\left[\left(D_{g}\left(p_{g}\right), \infty\right)\right.$. Hence, we consider $Q_{g}$ as a decision variable but still remain $U_{g}$ for a clear description.

\section{Model Analysis}

We can transform the objective function in Problem $(p 1)$ to $\pi_{g}=\left(p_{g}-p_{0}\right)\left(Q_{g}-L\right)+\pi_{0}$, where $p_{0}=B\left(p_{n}-c_{n}\right)+c_{g} L=B s\left(p_{n}-c_{n}\right)$ and $\pi_{0}=B\left(p_{n}-c_{n}\right) D_{g}\left(p_{0}\right)$. Figure 2 shows the objective function in three-dimension, which is like a saddle-shape centered at point $O\left(p_{0}, L, Z_{0}\right)$, where $Z_{0}=\pi_{0}$. 

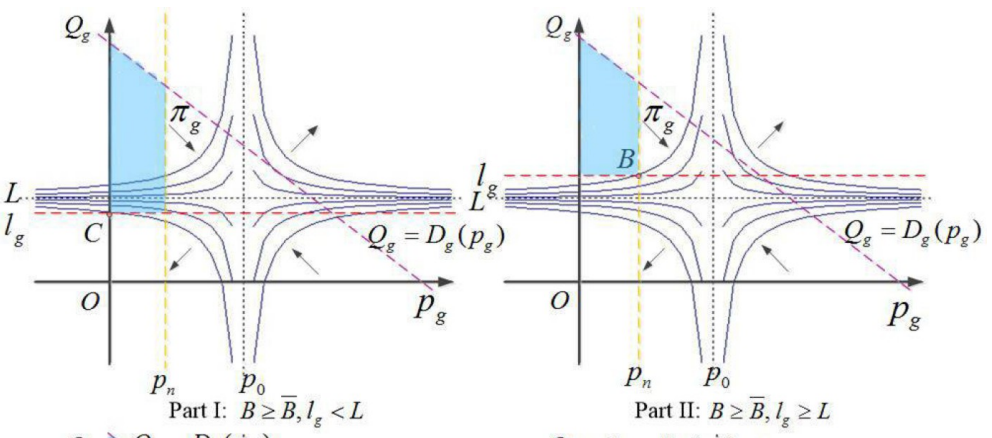

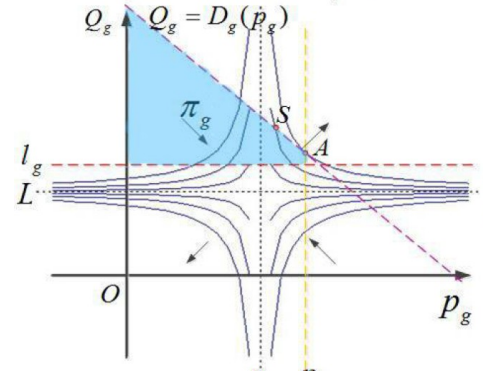

$p_{0} p_{n}$

Part III: $B<\bar{B}, l_{g} \geq L$

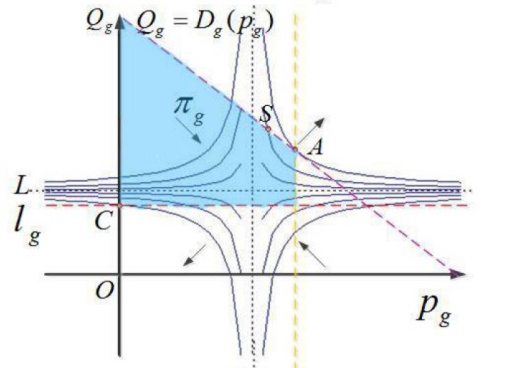

$p_{0} \quad p_{\underline{n}}$

Part IV: $B<\bar{B}, l_{g}<L$

Figure 3. Optimal strategies for seller's selling on Group-buying website

Next we show the meaning of parameter $L$ and $p_{0}$. When $Q_{g}=L$, sellers will obtain a same profit by setting either a high price or a low price on the GB website. We denote $\bar{L}=D_{g}\left(p_{n}\right)$, and assume that $L \leq \bar{L}$ since the transfer -and -buy rate is very small in the real life. $p_{0}$ is the minimum value of $p_{n}$ that satisfying a unit demand online is better than transferring it to offline. If $p_{n} \leq p_{0}$, it is easy to see $B \geq \bar{B}$, where $\bar{B}=\frac{p_{n}-c_{g}}{p_{n}-c_{n}}$. We then have $B\left(p_{n}-c_{n}\right) \geq \bar{B}\left(p_{n}-c_{n}\right)$ $=p_{n}-c_{g} \geq p_{g}-c_{g}$. The seller receives a higher profit from transferring an online customer to offline than from satisfying her/him directly online.

Figure 3 is the projection of Figure 2 on plane $p_{g}-Q_{g}$, which is centered on point $\left(p_{0}, L\right)$. The line $p_{g}=p_{0}$ and $Q_{g}=L$ divide the plane into four quadrants. The arrow in each quadrant indicates the increasing direction of the objective function. Although the objective function is neither concave nor convex, we can easily solve the optimal solution of Problem $(p 1)$ for each case in which the parameter pair $\left(p_{n}, I_{g}\right)$ locates in one of the four quadrants. In each case, the shaded area is the feasible solution. We illustrate the optimal solutions in Figure 3.

In Figure 3, Part I shows the feasible area when $p_{n} \leq p_{0}$ (i.e., $B \geq \bar{B}$ ) and $I_{g}<L$. Because $\partial \pi_{g}{ }^{\prime} / \partial Q_{g}=p_{g}-p_{0} \leq p_{n}-p_{0} \leq 0$, thus the objective function is decreasing in $Q_{g}$. The optimal solution must be on the line of $Q_{g}=I_{g}$, which is less than $L$. On this line, we have $\partial \pi_{g}{ }^{\prime} / \partial p_{g}=Q_{g}-L<0$. Therefore the optimal point has to be $C=\left(0, I_{g}\right)$. It corresponds to a strategy in which the seller sells the product at an extremely low price (much below the $\operatorname{cost} c_{g}$ ) or even for free on the GB site with a maximum deal size equal to minimum deal 
size in order to take advantage of ALA effect. We call this strategy as Low Price-ALA (LP-ALA).

Part II shows the feasible area when $p_{n} \leq p_{0}$ and $I_{g} \geq L$. In this case, $\partial \pi_{g}{ }^{\prime} / \partial p_{g}=Q_{g}-L \geq 0$ and $\partial \pi_{g}{ }^{\prime} / \partial Q_{g}=p_{g}-p_{0}<0$, thus the optimal point is obviously at $B=\left(p_{n}, l_{g}\right)$. It corresponds to the strategy called High Price-ALA (HP-ALA), which means the seller charges a high price approaching to that offline while using ALA effect.

Part III shows the feasible region when $p_{n}>p_{0}$ (i.e., $B<\bar{B}$ ) and $I_{g} \geq L$. Because $\partial \pi_{g}{ }^{\prime} / \partial p_{g}=Q_{g}-L \geq 0$ for $Q_{g} \geq I_{g} \geq L$, the optimal solution has to be on either the line $p_{g}=p_{n}$ or $Q_{g}=D_{g}\left(p_{g}\right)$. We can use K-T condition to solve this problem and derive the optimal point is either at Point $\left.S=\left(\frac{A+c_{g}}{2}, I\right)_{g}\left(\frac{A+c_{g}}{2}\right)\right)$ (where $\left.A=\frac{n_{g}+n \alpha}{r n_{g}+\alpha m n}, A \in\left(\frac{1}{r}, \frac{1}{m}\right)\right)$ or at Point $A=\left(p_{n}, D_{g}\left(p_{n}\right)\right)$. If $c_{g}<2 p_{n}-A, S$ is the optimal solution, otherwise $\mathrm{A}$ is the optimal one. In both cases, the seller sets no cap on the maximum deal size of GB sale and sells as many as the demand. We call this No Deal Size Limit (NDSL) strategy. Point A represents high price-NDSL while Point $S$ represents low price-NDSL.

Part IV shows the feasible region when $p_{n}>p_{0}$ and $I_{g}<L$. In this case, there are two subcases, one is that $p_{g}<p_{0}$, then we have $\partial \pi_{g}{ }^{\prime} / \partial Q_{g}=p_{g}-p_{0}<0$, thus the optimal solution must be on the line $Q_{g}=I_{g}$. Hence, we can derive $\partial \pi_{g}{ }^{\prime} / \partial p_{g}=Q_{g}-L<0$. Therefore, the optimal point is $C=\left(0, I_{g}\right)$ in this subcase. In the second subcase, $p_{g} \geq p_{0}$, then we have $\partial \pi_{g}{ }^{\prime} / \partial Q_{g}=p_{g}-p_{0} \geq 0$, which is similar to the situation of Part III. The optimal point may be Point $A$ or Point $S$ in this subcase. Finally, we need to compare the optimal solution from previous two subcases and derive the optimal one for Part IV. We summarize the result in Table 1.

Proposition 1. Sellers' optimal strategies for selling through GB website are affected by consumers' transfer-and-buy rate, fees for GB sale and the minimum deal size set by the GB website. The optimal strategies are summarized in Table 1. 


\begin{tabular}{|c|c|c|c|c|c|}
\hline \multicolumn{2}{|c|}{ Parameters } & \multicolumn{3}{c|}{ Optimal Strategies } \\
\hline \multirow{3}{*}{$\boldsymbol{B}$} & $c_{g}$ & $\boldsymbol{I}_{g}$ & $\boldsymbol{p}_{g}$ & $\boldsymbol{Q}_{g}$ & Description \\
\hline \multirow{3}{*}{$0, \bar{B}$} & \multirow{3}{*}{$\left(c_{n}, 2 p_{n}-A\right)$} & {$[0, R)$} & 0 & $I_{g}$ & LP-ALA \\
\cline { 2 - 5 } & \multirow{2}{*}{$2 p_{n}-A, p_{n}$} & {$[R, \bar{L}]$} & $\left(c_{g}+A\right) / 2$ & $D_{g}\left(\left(c_{g}+A\right) / 2\right)$ & NDSL \\
\cline { 3 - 6 } & \multirow{2}{*}[\overline{B},1]{} & {$[0, S)$} & 0 & $I_{g}$ & LP-ALA \\
\hline \multirow{2}{*}{$c_{n}, p_{n}$} & {$[S, \bar{L}]$} & $p_{n}$ & $\bar{L}$ & NDSL \\
\cline { 3 - 6 } & & {$[0, L)$} & 0 & $I_{g}$ & LP-ALA \\
\hline
\end{tabular}

$\left(L_{1}=\frac{B\left(n_{g}+n \alpha\right)\left(p_{n}-c_{n}\right)-\frac{\left(A-c_{g}\right)^{2}\left(n_{g}+n \alpha\right)}{4 A}}{B\left(p_{n}-c_{n}\right)+c_{g}}, L_{2}=\frac{B\left(n_{g}+n \alpha\right)\left(p_{n}-c_{n}\right)-D_{g}\left(p_{n}\right)\left(p_{n}-c_{g}\right)}{B\left(p_{n}-c_{n}\right)+c_{g}}, R=\max \left\{0, \min \left\{L_{1}, L\right\}\right\}, S=\max \left\{0, \min \left\{L_{2}, L\right\}\right\}.\right)$

Table 1. Optimal strategies for seller's selling on Group-buying website

As seen in Figure 4, we draw a decision tree for sellers and the numerical analysis is shown in Table 2.

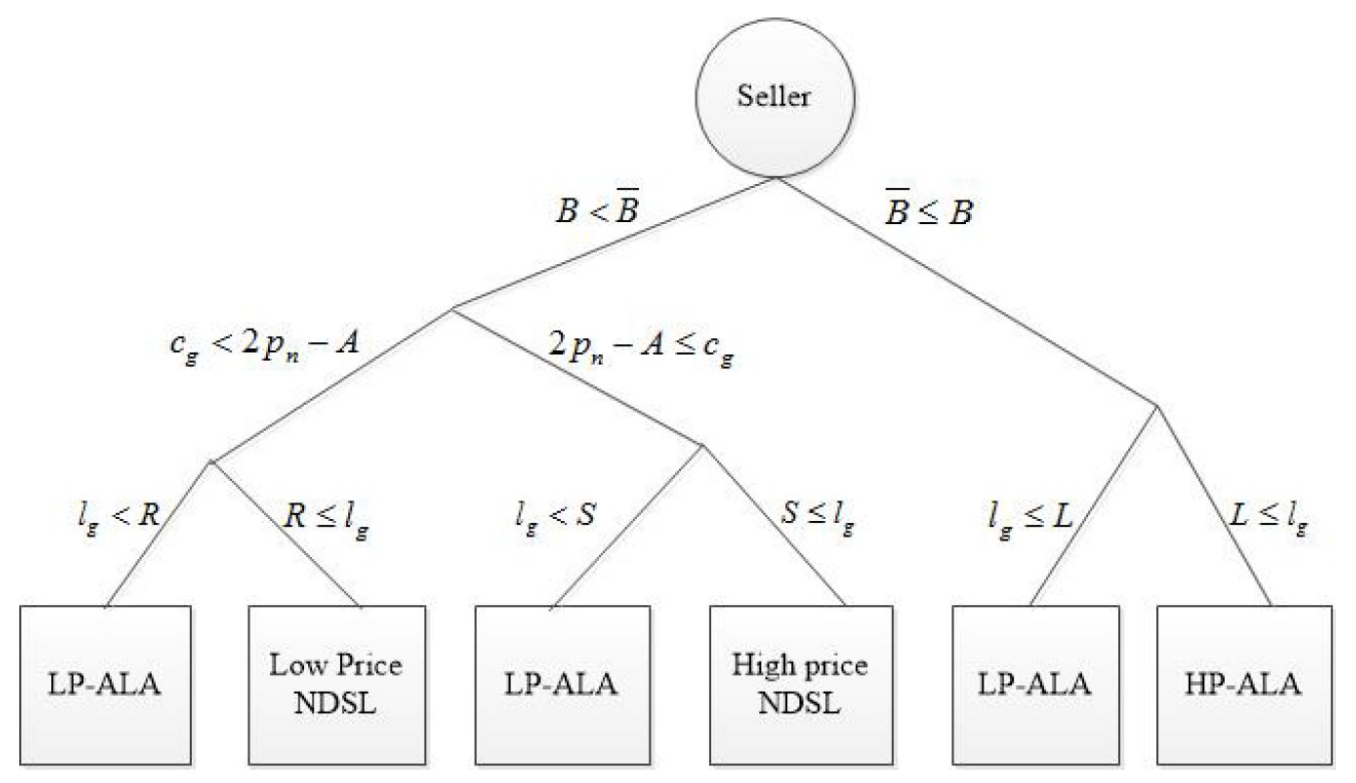

Figure 4. Decision tree for sellers 


\begin{tabular}{|c|c|c|c|c|c|}
\hline \multicolumn{2}{|c|}{ Parameters } & \multicolumn{5}{c|}{ Optimal Strategies } \\
\hline$c_{g}$ & $I_{g}$ & $p_{g}$ & $\boldsymbol{Q}_{g}$ & $\pi_{g}\left(\times 10^{4}\right)$ & Description \\
\hline 77.5 & 5 & 0 & 5 & 2.65 & LP-ALA \\
\hline 77.5 & 85 & 0 & 85 & 2 & LP-ALA \\
\hline 77.5 & 165 & 82.5 & 165 & 1.46 & HP-ALA \\
\hline 67.5 & 5 & 0 & 5 & 2.66 & LP-ALA \\
\hline 67.5 & 85 & 82.5 & 874.5 & 2.32 & NDSL \\
\hline 67.5 & 165 & 82.5 & 874.5 & 2.32 & NDSL \\
\hline 47.5 & 5 & 79.87 & 951.75 & 4.09 & NDSL \\
\hline 47.5 & 85 & 79.87 & 951.75 & 4.09 & NDSL \\
\hline 47.5 & 165 & 79.87 & 951.75 & 4.09 & NDSL \\
\hline
\end{tabular}

$\left(B=0.12, c_{n}=40, n_{g}=3000, n=1000, \alpha=0.3, m=0.008, r=0.009\right)$

Table 2. Numerical Analysis of Sellers' Optimal Strategies

\section{Managerial Insights}

From Table 1 we can see that strategies with deep discount (or even sell for free) can be the optimal ones. The key here is that maximum deal size controls the loss online and transfers the excess consumers to offline. Intuitively, deal size limits may be used only when sellers' capacity is not enough to meet all online demand. However, we show that:

Remark 1. Even if sellers' capacity is sufficient, the seller may still set an upper bound of deal size on the GB website to take advantage of ALA effects.

From Table1 we can also find that when transfer-and-buy rate $B$ is relatively high, i.e., $B \geq \bar{B}$, taking advantage of ALA effect is the best choice for the seller, since transferring one unit consumer to buy offline is more profitable than selling to them directly online. However, when $B$ is relatively low and the minimum deal size set by the GB website is relatively high, sellers prefer to use NDSL for selling to consumers directly online.

Note that the transfer-and-buy rate $B$ is proportional to the retention rate $\lambda$. It is easy to see that the thresholds of the lower bound, $R, S$ and $L$, in Table 1 are all increasing in the retention rate. A higher $\lambda$ implies a larger region of $I_{g}$ for the low price with limited availability strategy (LP-ALA) to be optimal. Thus, we have the following remark which is consistent with intuition:

Remark 2. With a higher retention rate $\lambda$, sellers are more likely to set a low price company with a low deal size limit to stimulate online demand and then transfer them to buy offline (i.e., LP-ALA strategy). 
From the definition of $B$ and $\bar{B}$, a lower offline price, $p_{n}$, implies a higher $B$ and a lower $\bar{B}$, thus $B>\bar{B}$ is more likely to be satisfied. We have the following remark:

Remark 3. Given all costs the same, low margin products are more suitable for being sold online with ALA strategies (LP-ALA or HP-ALA) than high margin ones.

The minimum deal size $I_{g}$ is also an important factor for the seller in selecting optimal strategies. In particular, it creates a barrier for the seller to offer deep discounts, for example, to utilize LP-ALA strategy, because she/he has to first sacrifice the profit margin on the items sold by the minimum deal size. The larger the minimum deal size $I_{g}$, the larger the sacrifice for the seller to take LP-ALA strategy. Therefore, deep discounts are less likely to be offered as $I_{g}$ increases. Thus we have the following remarks for the GB site operator:

Remark 4. If the GB site operator wants to induce discounts from the seller, he should set a small minimum deal size.

\section{To Groupon or not: Single channel VS. Dual channel}

We have solved the optimal strategy for the seller if GB sites are used. Intuitively, the GB sites are an additional selling channel and should not make the seller worse off. However, there are pros and cons for the seller to use online GB channel. On one hand, she may acquire a large number of new online consumers. On the other hand, she has to pay GB sale fee. Moreover, online coupons may erode existing consumer base that would pay a higher price otherwise.

In this section, we compare the seller's profits between the cases with and without GB sales and derive the conditions under which GB channel is indeed beneficial to the seller.

First, we solve the optimal price in the case of selling product offline only. The number of people buying the product is: $Q=n \varphi_{n}\left(p_{n}\right)$, and the profit for the seller is:

$$
\pi_{n}=n \varphi_{n}\left(p_{n}\right)\left(p_{n}=c_{n}\right)
$$

Maximizing (5), we get: $p_{n}{ }^{*}=\frac{1+m c_{n}}{2 m}, Q^{*}=\frac{n \varphi_{n}\left(c_{n}\right)}{2}$, and $\pi_{n}^{*}=\frac{n \varphi_{n}^{2}\left(c_{n}\right)}{4 m}$.

Comparing the profit of optimal strategies from the dual channel (denoted as DC) with that from single channel (denoted as SC), we have the following Proposition 2. 
Proposition 2. There exists a threshold for $n_{g}$ and $\alpha$ respectively. When $n_{g} \geq \overline{n_{g}}$ or $\alpha \leq \bar{\alpha}$, dual channel is better than single channel, if other parameters are fixed.

We provide a numerical study in Table 3 to illustrate how these two factors (i.e., $n_{g}$ and $\alpha$ ) change the choice of the channel structure. The optimal profit with a single offline channel $\pi_{n}{ }^{*}$ is $1.445 \times 10^{4}$ according to Equation (5). We compare this with the profit from dual channel. We define $\delta_{1}=\frac{\pi_{g}{ }^{*}-\pi_{n}^{*}}{\pi_{n}^{*}} \times 100 \%$, which is the percentage increase in profit between dual channel and single channel. If it is negative, single channel is better otherwise dual channel is better.

\begin{tabular}{|c|c|c|c|c|c|c|c|c|c|c|c|c|}
\hline \multicolumn{3}{|c|}{$\begin{array}{l}\text { Different } \\
\text { Conditions }\end{array}$} & \multicolumn{5}{|c|}{$\alpha=0.3$} & \multicolumn{5}{|c|}{$\alpha=0.6$} \\
\hline \multirow{2}{*}{$I_{g}$} & \multirow{2}{*}{$\boldsymbol{\lambda}$} & \multirow{2}{*}{$\boldsymbol{n}_{\boldsymbol{g}}$} & \multicolumn{4}{|c|}{ Optimal Strategies for DC } & \multirow{2}{*}{$\begin{array}{c}\text { DC vs.SC } \\
\delta_{1}(\%)\end{array}$} & \multicolumn{4}{|c|}{ Optimal Strategies for DC } & \multirow{2}{*}{$\begin{array}{c}\text { DC vs.SC } \\
\delta_{1}(\%)\end{array}$} \\
\hline & & & B & $p_{g}$ & $Q_{g}$ & $\pi_{g}\left(\times 10^{4}\right)$ & & B & $p_{g}$ & $Q_{g}$ & $\pi_{g}\left(\times 10^{4}\right)$ & \\
\hline \multirow{8}{*}{15} & 0.3 & 300 & 0.09 & 82.5 & 179 & 1.24 & -14.49 & 0.094 & 82.5 & 281 & 0.93 & -35.67 \\
\hline & 0.3 & 900 & 0.083 & 82.5 & 334 & 1.43 & -1.13 & 0.087 & 82.5 & 436 & 1.12 & -22.31 \\
\hline & 0.3 & 1500 & 0.081 & 82.5 & 488 & 1.62 & 12.24 & 0.084 & 82.5 & 590 & 1.32 & -8.94 \\
\hline & 0.3 & 2700 & 0.08 & 82.5 & 797 & 2.01 & 38.97 & 0.082 & 82.5 & 899 & 1.70 & 17.79 \\
\hline & 0.46 & 300 & 0.137 & 0 & 15 & 1.25 & -13.62 & 0.144 & 0 & 15 & 1.01 & -29.85 \\
\hline & 0.46 & 900 & 0.128 & 0 & 15 & 1.56 & 7.32 & 0.134 & 0 & 15 & 1.32 & -8.9 \\
\hline & 0.46 & 1500 & 0.125 & 0 & 15 & 1.85 & 28.24 & 0.129 & 0 & 15 & 1.62 & 12.02 \\
\hline & 0.46 & 2700 & 0.12 & 0 & 15 & 2.46 & 70.05 & 0.125 & 0 & 15 & 2.22 & 53.84 \\
\hline
\end{tabular}

$\left(c_{n}=40, c_{g}=70, n=1000, m=0.008, r=0.009\right)$

Table 3. Seller's channel decision

From Table 3, we observe that with increasing $n_{g}$ dual channel tends to be better than single channel. For example, when $I_{g}=15, \alpha=0.3$ and $\lambda=0.3$, we have $\delta_{1}$ to be negative if $n_{g}$ is below 900 . As $n_{g}$ increases to $1500, \delta_{1}$ becomes positive and dual channel is better.

The market overlap $\alpha$ also affects the channel selection. If we fix all other factors and decrease $\alpha$, dual channel also tends to be better. In Table 3, when $I_{g}=15, \lambda=0.3$ and $n_{g}=1500$, dual channel is better than single channel when $\alpha=0.3$ but the opposite is true when $\alpha$ increases to 0.6. The profit from dual channel decreases as $\alpha$ increases. This is because the overlap reduces the number of offline high-value customers buying offline at original price. 


\section{Conclusions}

Sellers sell on GB sites at a service charge mainly for reaching many new consumers. Online GB sales have two typical characteristics: A minimum deal size limit set by GB sites to guarantee their revenue from each deal and an option for sellers to set a maximum deal size limit. We investigate the optimal strategy for sellers selling on GB website in this paper.

We find that even if the sellers' capacity is sufficient, the seller may still set a cap on the maximum deal size to take advantage of ALA effect. Even optimal GB selling strategies are used, dual channel may not bring a higher profit than selling through offline channel alone when a GB site only has a small consumer base and/or if there is a big overlap between the online and offline markets. Low margin products are more suitable for being sold online with ALA strategies (LP-ALA or HP-ALA) than high margin ones. Besides the above managerial insight for the seller, this paper also gives the GB website operator suggestions on how to induce sellers' deep discounts—setting a small minimum deal size.

This paper is a first attempt to examine the seller's GB sale decision problem regarding to price and bounds on deal sizes. There are still many issues that can be investigated in the future research. For example, it will be interesting to study how stochastic demand and a more general demand function affect the optimal strategies. The gaming behaviors between GB sites and sellers are also an interesting direction we can explore.

\section{Acknowledgment}

This paper is sponsored by the National Natural Science Foundation of China (Project No. 70971047, 71371078). The author would like to appreciate the financial support from the projects.

\section{References}

Anand, K.S., \& Aron, R. (2003). Group buying on the web: A comparison of price-discovery mechanisms. Management Science, 49(11), 1546-1562.

Anily, S., \& Hassin, R. (2013). Pricing, replenishment, and timing of selling in a market with heterogeneous customers. International Journal of Production Economics, 145(2), 672-682.

Anonymous (2011). Groupon 'Flaw' In the Business. Wall Street Journal, January 7. Retrieved from http://online.wsj.com/article/SB10001424052748704739504576068131907479632.html (Last access date: December 2013). 
Aydin, G., \& Porteus, E.L. (2009). Manufacturer-to-retailer versus manufacturer-to-consumer rebates in a supply chain//Retail Supply Chain Management. Springer US, 237-270.

Chen, J., Kauffman, R.J., Liu, Y., \& Song, X. (2010). Segmenting uncertain demand in group-buying auctions. Electronic Commerce Research and Applications, 9(2), 126-147.

China Electronic Commerce Research Center (CECRC) (2012). 2012 Network group buying market data monitoring report. http://www.100ec.cn/zt/upload_data/wenjian/2012tgbg.pdf

Demirag, O.C., Keskinocak, P., \& Swann, J. (2011) Customer rebates and retailer incentives in the presence of competition and price discrimination. European Journal of Operational Research, 215(1), 268-280.

Dholakia, U. (2011). How Businesses Fare with Daily Deals: A Multi-Site analysis of Groupon, Livingsocial, Opentable, Travelzoo, and Buywithme promotions. Working Paper. Rice University, Houston, USA.

Dholakia, U., \& Tsabar, G. (2011). A startup's experience with running a Groupon promotion. Working Paper. Rice University, Houston, USA.

Edelman, B., Jaffe, S., \& Kominers, S.D. (2011). To Groupon or not to Groupon: The profitability of deep discounts. Working Paper. Harvard University, Boston, USA.

Geng, Q., \& Mallik, S. (2011). Joint mail-in rebate decisions in supply chains under demand uncertainty. Production and Operations Management, 20(4), 587-602.

Hoch, S.J., Kim, B., Montgomery, A.L., \& Rossi, P.E. (1995). Determinants of store-level price elasticity. Journal of Marketing Research, 32(1), 17-29.

Hu, M., Shi, M., \& Wu, J. (2013). Simultaneous vs. sequential Group-Buying mechanisms. Management Science, forthcoming.

Jing, X., \& Xie, J. (2011). Group Buying: A new mechanism for selling through social interactions. Management Science, 57(8), 1354-1372.

Li, C., Sycara, K., \& Scheller-Wolf, A. (2010). Combinatorial coalition formation for multi-item group-buying with heterogeneous customers. Decision Support Systems, 49(1), 1-13.

Luo, X., Andrews, M., Song, Y., \& Aspara, J. (2013). Group-buying deal popularity. Journal of Marketing, forthcoming.

Qian, D. (2013). Optimization decision making for agency commission in online group buying. Doctoral dissertation. Donghua University, Shanghai, China. 
Tuten, T.L., \& Ashley, C. (2011). Promotional strategies for small businesses: group buying deals. Small Business Institute Journal, 7(2), 15-29.

Zhang, X. (2009). Retailers' multichannel and price advertising strategies. Marketing Science, 28(6), 1080-1094.

Zhang, X. (2013). Research on development strategies of Meituan. Master dissertation. Shandong University, Shandong, China.

Journal of Industrial Engineering and Management, 2014 (www.jiem.org)

Article's contents are provided on a Attribution-Non Commercial 3.0 Creative commons license. Readers are allowed to copy, distribute and communicate article's contents, provided the author's and Journal of Industrial Engineering and Management's names are included. It must not be used for commercial purposes. To see the complete license contents, please visit http://creativecommons.org/licenses/by-nc/3.0/. 